\title{
Berger, J. y Mohr, J. (2018). Un séptimo hombre. Imágenes y palabras sobre la experiencia de los trabajadores emigrantes en Europa
}

\author{
Juan Cruz Margueliche \\ jcruzmargueliche@gmail.com \\ Centro de Investigaciones Geográficas (CIG). Instituto \\ de Investigaciones en Humanidades y Ciencias Sociales. \\ Facultad de Humanidades y Ciencias de la Educación - \\ Universidad Nacional de La Plata, Argentina
}

Recepción: 26 Junio 2020

Aprobación: 14 Julio 2020

Publicación: 02 Noviembre 2020

Cita sugerida: Margueliche, J. C. (2020). [Revisión del libro Un séptimo hombre. Imágenes y palabras sobre la experiencia de los trabajadores emigrantes en Europa por J. Berger y J. Mohr]. Geograficando, 16(2), e079. https://doi.org/10.24215/2346898Xe079

\footnotetext{
"Un séptimo hombre puede ser abordado como una especie de álbum de familia por aquellos que se vieron obligados a abandonar a sus familias" (p. 11).
}

\section{INTRODUCCIÓN A LA OBRA}

La obra se publicó por primera vez en el año 1975, por lo cual muchas de las estadísticas y países mencionados en el libro no responden a una situación actual sino a un recorte espacio temporal determinado. Sin embargo, muchas de sus apreciaciones y análisis del sistema capitalista con relación a la movilidad de personas están aún vigentes. La propuesta del libro fue indagar la experiencia de los trabajadores $^{1}$ emigrantes de la Europa más relegada hacia la Europa “poderosa y rica” (Gran Bretaña, Francia y Alemania). Pero lleva adelante esta propuesta relacionando el contexto de vida de las personas que 
deciden emigrar a través de diferentes temporalidades: el presente (el viaje y el trabajo), el pasado (a través de los recuerdos) y el futuro (la imaginación como recurso). El libro nos permite comprender la realidad social y política del mundo a diferentes escalas, más allá de las grandes teorías emergentes de aquella época.

El libro cuenta con tres apartados: "la partida", "el trabajo" y "el regreso". Cada uno de estos apartados mantiene autonomía a través de su especificidad expresando situaciones diferentes que las personas que deciden emigrar deben afrontar. No obstante, estas etapas se encuentran hilvanadas por sentimientos comunes: la esperanza de lograr exitosamente la emigración (cruzar la frontera) y el sueño de poder vivir mejor.

El libro está compuesto por una gran diversidad de formas narrativas y visuales. Estamos en presencia de una propuesta que mezcla pasajes de poesía, análisis socioantropológicos, entrevistas, observaciones, mapas y fotografías (de rostros, situaciones cotidianas, actividades de ocio y laborales, obras en construcción, entre otras). Esta diversidad discursiva y organizativa-estética hace que la obra no se pueda encasillar fácilmente y la podamos transitar con todo su potencial enunciativo, abriendo el juego a los/las lectores/as a elegir qué y cómo apropiarse de la obra.

Los datos que el libro sistematiza nos dicen que: en aquella época en Alemania (y en Gran Bretaña) uno de cada siete trabajadores manuales era emigrante; que las tres cuartas partes (3/4) de las personas que llegaban se dirigen a los dos países mayores: Francia y Alemania; que las dos terceras partes (2/3) trabajaban en la industria, la construcción o las obras públicas, y solo una pequeña parte en la agricultura. El resto va a trabajar en el sector de servicios.

La propuesta de los autores fue mostrar hasta qué punto la economía de las naciones ricas de Europa había pasado a depender, en la década de 1960, de la mano de obra que procedía de varias naciones pobres del mismo continente. Pero también el objetivo de Berger y Mohr fue una propuesta de interés político, ya que buscaban alentar la solidaridad internacional de la clase obrera. Cosa que no sucedió.

En el prólogo del año 2002 (nueva edición de la original) Berger interpela su obra en retrospectiva buscando la (re)funcionalidad de esta en el tiempo presente. Para Berger estamos ante "un libro que rejuvenece con el paso del tiempo".

\section{Recursos y METOdologías}

El libro cuenta con diferentes recursos que permiten al lector superar los análisis teóricos y acercarnos a la mirada desde los actores. Las imágenes que se exhiben en el libro son fotografías tomadas a lo largo de varios años por J. Mohr. Las palabras y las fotografías, si bien son recursos expresivos diferentes, en el libro no buscan deslegitimarse sino potenciarse, permitiendo adentrarnos en la temática de una manera situada.

"Toda fotografía es un medio de transporte y la expresión de una ausencia” (p. 21). La perspectiva de Mohr se nos presenta como un "álbum que está vivo". Las palabras junto a las fotos actúan como una propuesta dinámica, siempre en movimiento, y se van resignificando a lo largo de la obra.

La obra, a través de muchas fotografías de infraestructuras (la mayoría construidas por la emigración) muestra las nuevas accesibilidades y conectividades entre pueblos, ciudades y personas. El libro también muestra todas las dificultades y peripecias que los emigrantes deben superar, tanto para llegar al país receptor como para quedarse. La paradoja se da en que las mismas personas que permitieron la conexión entre lugares a través de la mano de obra migrante son las que padecen la falta de acceso al mismo espacio más tarde.

Otras metodologías que podemos identificar en el libro se basan en observaciones, entrevistas y sobre todo en reflexiones de corte socioantropológico que permiten conocer desde la mirada de los protagonistas.

Los autores también les dan un lugar a las temporalidades como construcciones sociales. Estas entran en juego en la cosmovisión del emigrante para sostenerse en la vida cotidiana. En este sentido, el presente se vive en el trabajo (de corte utilitario e instrumentalista), pero rápidamente se retroalimenta del pasado (como soporte subjetivo que lo contiene -recuerdos-) y del futuro como un imaginario que busca proyectarse en 
condiciones materiales (les permite sostenerse). Según Berger, en la imaginación se encuentra otro recurso para poner en juego a la hora de abordar esta temática. Todo trabajador emigrante se siente de paso, ya que todo el tiempo recuerda su pasado, imagina su futuro, donde sus recuerdos hacen que sus pensamientos se conviertan en una especie de tren que circula entre los dos pasajes temporales. La imaginación es un recurso transtemporal donde logra ingresar desde el tiempo presente al pasado y al futuro. Es un recurso difícil para la acción empírica pero que le permite al emigrante poder sobrevivir a las consecuencias concretas que lo interpelan diariamente.

También Berger nos invita a reflexionar sobre caminos complementarios entre las grandes teorías y otras prácticas menos abstractas. Para ello sostiene que, si se desea comprender las fuerzas que condicionan la vida de un emigrante y poder visualizarlas como parte de su destino individual, se debe recurrir a diferentes formas de explicación. Para el autor no alcanza con el lenguaje de la teoría económica. Por ello es que hay que recurrir a la metáfora, dice Berger. Pero nos aclara que la metáfora es de carácter pasajero y no puede sustituir a la teoría. En este sentido, nos advierte que la teoría económica puede demostrar por qué el sistema genera subdesarrollo y qué condiciones propician la emigración. Por lo cual, no podemos y no debemos abandonar la teoría, aunque tampoco hay que dejar de lado las perspectivas que nos acercan a la visión de los actores.

Para intentar comprender la experiencia del otro, es necesario desmontar el mundo tal y como uno lo ve desde el lugar que ocupa en él, y tratar de volver a montar bajo la óptica propia del lugar ocupado por el otro (p. 100).

La obra nos "empuja” a (re)encontrarnos con sensaciones y sentidos de la trayectoria migratoria. El trabajo de escalas también nos permite comprender cómo los grandes procesos del sistema capitalista se adhieren a la vida cotidiana de estos/as trabajadores/as desde la migración del campo a la ciudad, de los diferentes cruces fronterizos como así también en las tres epatas de la migración: salida, llegada y retorno.

\section{LA ESPACIALIDAD EN LA OBRA}

Como geógrafos/as no podemos dejar de leer la obra desde sus emergentes territoriales y los impactos que genera el proceso migratorio en los diferentes lugares que atraviesa la trayectoria migratoria.

En este sentido, encontramos un interesante análisis sobre la configuración y rol de la ciudad. Una ciudad como artefacto económico y cultural que invitaba a las personas a vivir entre imaginarios y promesas. Como diría Sarlo: "La ciudad no ofrece a todos lo mismo, pero a todos les ofrece algo, incluso a los marginales que recogen las sobras producidas por los incluidos” (2009, p. 13). ${ }^{2}$ Por otro lado, Berger afirma, a partir de su investigación: "Lo que la ciudad ofrece está destinado a quienes triunfan en ella, no a quienes fracasen" (p. 41).

En la ciudad se asumía el supuesto de que dos personas extrañas nunca se encontrarían dos veces. Esta situación que solo la vida de las grandes ciudades iba generando, permitía el anonimato de las personas. En este sentido las relaciones entre las personas se modifican radicalmente (a diferencia de las zonas rurales). La ciudad alberga al europeo nativo y a los europeos provenientes de diferentes naciones. Pero lo hace desde un espacio que no busca encontrarlos.

Berger habla de la naturalidad de la condición inferior y de las etiquetas que la metrópoli impone cotidianamente. Analiza la fuerte discriminación y estigmatización de los europeos sobre los "otros" europeos. Se hablaba de "los negros de Europa” para edificar una pirámide jerárquica entre hombres iguales. Se hablaba de sus hábitos, del hábitat y de que solo les importaba el dinero. "No saben vivir en una ciudad moderna. Tardarán cien años en aprender (...) Nuestras callejuelas son auténticos palacios para ellos” (p. 120).

Según esta obra, la igualdad no tiene que ver con la capacidad o función, sino con el reconocimiento.

Otra espacialidad que se observa en el libro se refiere a la disposición de los emigrantes dentro de la fábrica. Este es el caso de los trabajadores al mando de las cadenas de montaje y el estudio de sus cuerpos como mapa del movimiento dentro de la fábrica (ver p. 111). 
También se destaca el rol de los medios de transporte que actúan como espacios de desplazamientos, encuentro y contacto, reflexión y relaciones. Las estaciones de ferrocarril eran lugares de reunión y encuentro. Esto refleja cómo hay una negación y segregación de los espacios públicos y comunes. Ser emigrante es configurar los propios espacios de ocio y esparcimiento. Su condición de trabajador permanente pareciera negarle en el espacio otras conductas y acciones.

\section{Cruzando las fronteras: estrategias para el ÉXito o EL Fracaso}

Berger habla de la frontera como de un espacio en continuum que se debe leer en un pasaje (de éxito o de fracaso) donde no solo cambian las condiciones de vida sino también las formas de acceder y habitar. El aporte de Berger en relación con la frontera podemos encontrarlo a través de las tres formas de cruzarla o atravesarla que describe:

Hacerse pasar por turistas: dependía de varias cuestiones externas al emigrante. Acceder a comprar un boleto de primera confiando en que el compartimiento de esa primera clase esté bien nutrido de personas ricas para evitar preguntas. O poder mostrar ante una inspección la suficiente cantidad de dinero para aparentar ser un verdadero turista.

Pagando 350 dólares a un guía: monto que en aquella época era equivalente al ingreso anual de un campesino medio. Para evitar ser timado y quedar varado en el trayecto utilizaban una foto y la partían a la mitad. Le daban una parte al guía y otra se la quedaban en su poder. Si el cruce era exitoso les avisaban a otros integrantes de la familia. De esta manera el guía presentaba el fragmento de la foto para validar la operación.

Aprobar una especie de prueba de calidad: se refería a las diferentes pruebas médicas (vista, altura, etc.) que apuntaban a dar certificación de calidad o de marginalidad. En este sentido, los rotulaban y los aptos eran separados para pasar a los exámenes profesionales.

\section{EL RETORNO}

El regreso del emigrante queda plasmado en el siguiente pasaje del libro:

Cuando se afeita en el pasillo del tren, estudia el rostro que le devuelve el espejo con mirada crítica, durante meses, ese rostro sólo le ha mirado de reojo, con complicidad. Al fin vuelve a ser el mismo y a reconocerse como tal. Lo que tuvo que ocultar durante once meses resultará ahora evidente para cuantos lo vean: que no es una persona inferior sino superior (p. 220).

Según Berger, para convertirse de nuevo en hombre el migrante debía retornar a su lugar de origen. En esta acción volvía a ser esposo, padre, ciudadano, patriota, etc.

"Los emigrantes no emigran en calidad de hombres, sino en calidad de maquinistas, barrenderos, poceros, mezcladores de hormigón, empleados de limpieza, taladradores, etc." (p. 66).

"(...) son inmortales (...) porque son siempre intercambiables. No nacen, no tienen que crecer, no envejecen, no se agotan, no se mueven. Tienen una sola función: trabajar” (p. 71).

Pero cuando al fin lograba volver las condiciones de vida de sus pueblos siguen sustentando las mismas condiciones que lo obligaron a emigrar. Tarde o temprano el ciclo de la emigración vuelve a activarse.

\section{Notas}

1 Se utiliza el género masculino en este caso porque la mayoría de los emigrantes de esta obra son hombres. Se muestra la situación de las mujeres en las zonas rurales o en aldeas, en los mercados o en las viviendas.

2 Ver Ciudad vista. Mercancías y cultura urbana (2009). Ciudad Autónoma de Buenos Aires: Editorial Siglo XXI. 